DOI:

\title{
SYMBOLICS OF CHINA REALIA IN RUSSIAN VERBAL CULTURE (IN THE ASPECT OF TEACHING RUSSIAN AS A FOREIGN LANGUAGE)
}

\author{
Veronika Abramova \\ Candidate of Philological Sciences, Associate Professor \\ Tula State Lev Tolstoy Pedagogical University \\ (Tula, Russia) \\ e-mail: istinijobraz@mail.ru \\ Julia Arkhangelskaya \\ Senior Researcher \\ Tula State Lev Tolstoy Pedagogical University \\ (Tula, Russia) \\ e-mail: archangelju@yandex.ru
}

\begin{abstract}
The authors of the article present a method, which has been worked out and tested by them and which is intended to help Chinese students in studying Russian lexical and phraseological units with a symbolic component referring to China and the Chinese (e.g. the lexical unit китаец in certain contexts can represent a personalized symbol of cunning; the phraseological unit китайская стена stands for a symbol of strength and insularity or excessive length of a building etc.). Knowledge of these units is urgent for foreign learners because it enables them to avoid culture shock and communicative shock when dealing with the Russians and facilitates communication with them. The method presupposes familiarizing students with symbolic meaning, etymology and usage specificity of the Russian lexical and phraseological units about China and the Chinese (китаец, шанхай, китайская грамота, китайская стена, китайские иеремонии, последнее китайское предупреждение, etc.), practicing usage of these units in speech, comparing them with the Chinese ethnic stereotypes about the Russians.
\end{abstract}

Keywords: verbal symbol, lexical and phraseological units with a symbolic component, China realia in the Russian linguistic worldimage, methodology of teaching Russian as a foreign language

\section{СИМВОЛИКА КИТАЙСКОГО В РУССКОЙ ВЕРБАЛЬНОЙ КУЛЬТУРЕ (В АСПЕКТЕ ПРЕПОДАВАНИЯ РКИ) *}

\author{
Вероника Абрамова \\ кандидат филологических наук, доцент \\ Тульский государственный педагогический университет им. Л.Н. Толстого \\ (Тула, Россия) \\ e-mail: istinijobraz@mail.ru \\ Архангельская Юлия \\ старший научный сотрудник \\ Тульский государственный педагогический университет им. Л.Н. Толстого \\ (Тула, Россия) \\ e-mail: archangelju@yandex.ru
}

\begin{abstract}
Аннотация. Авторы статьи представляют разработанную и апробированную ими методику, которая призвана помочь китайским студентам в изучении русских лексических и фразеологических единиц с символьной составляющей о Китае и китайцах (например, лексема китаеи в определенных контекстах может выступать как персонализированный символ хитрости; фразеологизм китайская стена как символ неприступности/изолированности или непомерной длины строений и т. п.). Знакомство с данными единицами актуально для иностранных учащихся, поскольку позволит им избежать культурного и коммуникативного шока при общении с русскими людьми и облегчит коммуникацию с ними. Разработанная методика предполагает знакомство студентов с символьным значением, этимологией, особенностями употребления русских лексем и фразеологизмов о Китае и китайцах (китаеи, шанхай, китайская грамота, китайская стена, китайские иеремонии, последнее китайское предупреждение и др.), отработку речевого применения данных единиц, сопоставление их с китайскими этностереотипами о русских людях.
\end{abstract}

Ключевые слова: вербальный символ, лексические и фразеологические единицы с символьной составляющей, китайское в русской языковой картине мира, методика РКИ

ВВЕДЕНИЕ. В последние десятилетия укрепляются отношения между Россией и Китаем в области политики, экономики и культуры, что способствует укреплению позиций русского языка в Китае и увеличению

\footnotetext{
* Исследование выполнено при поддержке Российского фонда фундаментальных исследований (грант № 19-512-18008). Название проекта: «Символика русских и болгарских вербальных текстов культуры»
} 
количества китайских студентов, желающих его изучать. В связи с этим представляется актуальной разработка различных методических аспектов проблемы обучения китайских студентов русскому языку как иностранному. Один из них - изучение лексических и фразеологических единиц, в которых закрепились стереотипные представления русских о Китае и китайцах. Узнав, как их нация выглядит «со стороны», студенты поймут, какие культурные реалии, связанные с их родиной, кажутся в стране изучаемого языка актуальными, к какой реакции «на себя» нужно быть готовым, чтобы избежать культурного и коммуникативного шока.

Таким образом, целью нашего исследования стала разработка и апробация методики, которая поможет китайским студентам в изучении русских лексических и фразеологических единиц с символьной составляющей о Китае и китайцах. В связи с этим были решены следующие задачи: 1) выявление корпуса лексем и фразеологизмов, отражающих представления о Китае и китайцах в русской языковой картине мира, и их анализ; 2) определение методики работы с данными единицами на занятиях по русскому языку как иностранному в китайской аудитории; 3) апробация и оценка продуктивности (проведение занятий и контрольный срез).

Анализ корпуса собранных лексических и фразеологических единиц показывает, что в русской языковой картине мира существует два основных этностереотипа, которые отражают представления о Китае и китайцах: 1) интенсивно выраженное (сложное, непонятное, странное и др.); 2) плохое, некачественное. Единицы первой группы традиционны для русского сознания и часто имеют давнюю историю. К ним относятся такие слова и фразеологизмы, как китаеи - 'очень хитрый человек'; китайский - 'странный, непривычный; сложный, запутанный, мудреный’; китайская стена - 'нечто очень длинное' или 'нечто непреодолимое'; китайская грамота - 'нечто очень непонятное, недоступное пониманию’; китайские церемонии - 'излишняя, жеманная вежливость'; китайский болванчик - 'человек, пассивно соглашающийся с остальными', а также 'крайне самодовольный, ограниченный человек'; китайское терпение - 'терпение, проявленное в максимальной степени'; последнее китайское предупреждение - 'одна из угроз в бесконечном ряду предупреждений’; как сто китайцев - 'очень / сильно (хитрый, голодный, усталый, злой и др.)'; утро китайского пчеловода/утро в китайской деревне - 'очень отекшее лицо, чрезмерно сузившиеся глаза человека наутро после бурно проведенной ночи'; китайский разведчик / шпион - 'очень хитрый, загадочный человек', а также 'излишне бдительные отец или мать' (в речи подростков); как до Пекина / Китая раком/пешком - 'очень далеко’ или 'очень долго'; как до китайской Пасхи - 'никогда'. Объективацией интенсивности в значении лексических и фразеологических единиц обычно служат наречия «очень», «слишком», «крайне», «чрезвычайно», «сильно», «совершенно» и др.

Единицы второй группы относительно новые, они начали фиксироваться с 90-х годов XX века. В них отражаются представления о китайском как о некачественном. Видимо, это связано с тем, что в постперестроечную эпоху в России были востребованы дешевые товары китайского производства, не отличавшиеся высоким качеством. Это слова и фразеологизмы шанхай - 'бедный, грязный, тесно застроенный, густонаселенный район города', 'трущобы'; два из четырех омонимов, существующих в русском языке: китайка1 - 'рынок, на котором продают дешевые китайские товары', 'сами эти товары'; китайка2 'постельное белье, которое, будучи уже использованным пассажирами, выдается проводником поезда другим пассажирам без стирки', отсюда скинуть (задвинуть, загнать и т.n.) китайку кому-либо 'выдать пассажиру поезда нестираное белье', а также получить белье из китайской прачечной - 'получить нестиранное белье (обычно в поезде)'; дядюшка / дядя Ляо - 'нелегальный производитель китайских некачественных товаров (в основном - техники)'; носки Шаолиня - 'некачественные сигареты' (очень крепкие, сделанные из некачественного сырья, с плохим запахом).

Во многих из указанных единиц присутствует символьная составляющая (например, лексема китаец в определенных контекстах может выступать как персонализированный символ хитрости; фразеологизм китайская стена - как символ неприступности / изолированности чего-либо или непомерной длины строений и т. п.), что повышает их культурную значимость.

Подробнее о значениях, этимологии и употреблении данных единиц можно прочитать в нашей статье «От китайской грамоты до дядюшки Ляо: развитие представлений о Китае и китайцах в русской языковой картине мира (на материале лексики и фразеологии)» (Abramova and Arkhangelskaia, 2019).

Нами были подготовлены методические материалы для занятия с китайскими студентами, изучающими русский язык: таблица, включающая столбцы с отобранными преподавателем единицами и пустые столбцы для фиксации их значений, которые должны заполнить сами студенты в ходе работы со словарями; визуальный ряд в форме презентации Microsoft Office PowerPoint, иллюстрирующий фразеологизмы и лексемы; система упражнений, направленных на запоминание и отработку речевого применения изучаемых единиц (узнать единицу по картинке-иллюстрации, выбрать и вставить единицу в предлагаемый контекст, придумать контекст для разных единиц).

Занятие по изучению русских фразеологизмов и лексем, отражающих представления о Китае и китайцах, было проведено на международном факультете Тульского государственного педагогического университета им. Л.Н. Толстого в группах китайских студентов и стажеров (уровень владения языком - А2 и Б1). В конце урока был проведен контрольный срез: студентам предлагалось ответить на вопросы специально разработанных анкет.

ОБЗОР ЛИТЕРАТУРЫ. Для определения значений русских стереотипов о Китае и китайцах (слов и устойчивых сочетаний) в настоящем исследовании были использованы лексико- и фразеографические издания: толковые и этимологические. Так, дефиниции единиц первой группы с общим значением интенсивности 
определялись по «Словарю современного русского литературного языка» в 17-ти томах (Slovar' sovremennogo russkogo literaturnogo yazyka 1950 - 1965), а также по словарю под редакцией Д.Н. Ушакова (Ushakov 1928 1940). Для определения семантики единиц второй группы с общим значением 'плохой, некачественный' мы использовали словари, изданные за последние 10-15 лет, поскольку это единицы новые и более ранние лексикогафические источники их еще не фиксируют. Кроме того, лексемы и фразеологизмы второй группы это единицы со сниженной стилевой окраской, присущие русской живой разговорной экспрессивной речи. В связи с этим для определения их значений необходимо было использовать аспектные толковые словари, в которых собраны преимущественно субстандартные единицы и экспрессивы: «Большой словарь русской разговорной речи» В.В. Химика (Khimik 2004) и «Толковый словарь русского сленга» В.С. Елистратова (Yelistratov 2010). Некоторые единицы настолько современны, что их еще не успели зафиксировать в словарях. Для их отбора использовались Интернет-сайты, например, сайт «Живой русский язык» (https:/vk.com/skazanul), а также данные Национального корпуса русского языка. Помимо этого в некоторых случаях для мотивации значения фразеологизмов требовались этимологические справки, для чего привлекался «Словарь русской фразеологии. Историко-этимологический справочник» А.К. Бириха, В.М. Мокиенко, Л.И. Степановой (Вirich et. al., 1999).

При анализе значений, определении роли отобранных языковых единиц в русской языковой картине мира и их классификации мы опирались на концепцию А.Д. Шмелева, согласно которой «представления, формирующие картину мира, входят в значения слов в неявном виде» и эти неявные компоненты смысла нередко «повторяются в значении целого ряда языковых единиц, представляя собою своего рода “сквозные мотивы" языковой картины мира» (Shmeljov 2009).

Говоря о символике отобранных языковых единиц, мы брали за основу тезис М.Л. Ковшовой о том, что «фразеологизм, транслируя в речи тот или иной устойчиво воплощенный в знаке культурный смысл, начинает играть роль оязыковленного символа, или вербального символа культуры» (Kovshova 2012).

На необходимость учитывать русские стереотипы в практике обучения русскому языку иностранцев в последние годы обратили внимание многие специалисты, в частности Ю.Е. Прохоров (Prohorov 2006). Исследователи также отмечают трудности, возникающие у китайских студентов-русистов в процессе изучения РКИ и связанные с различиями в этнокультурных традициях (Shanturova, 2015).

В ходе исследования использовались элементы этноориентированной методики, о важности которой говорится в статье А.К. Новиковой «Об учёте принципов этноориентированного обучения в системе занятий по РКИ (на примере китайской аудитории)» (Novikova, 2014). Материалом для занятия частично послужил текст статьи Ма Цзэхуэй и Н.В. Николаевой «Китайские стереотипы о русских в зеркале китайских анекдотов» (Jiehuі Ma \& Nikolaeva 2017).

МЕТОДЫ ИССЛЕДОВАНИЯ. Основными методами нашего исследования были: теоретический анализ научных исследований и корпуса словарей; опытно-экспериментальная работа, в ходе которой китайские студенты под руководством преподавателя изучали русские фразеологизмы и лексемы, отражающие представления о Китае и китайцах. Выполняя специально разработанные для занятий упражнения, учащиеся осуществляли познавательные и общеучебные универсальные действия, такие как умение осуществлять направленный поиск (определение значений изучаемых единиц с привлечением словарей и интернетисточников), обработку (заполнение таблицы) и использование информации (соотнесение единиц с контекстом и визуальным рядом), осознанно и произвольно строить речевое высказывание в устной и письменной форме.

В рамках этноориентированной методики проводилось сопоставление русских и китайских этностереотипов о китайских и русских именах, которые отражаются, например, в русском детском фольклоре и китайских анекдотах. Так, в известной русской скороговорке «Жили-были три китайца...» китайские имена представлены в утрированно сложном виде (Як, Як-Цидрак, Як-Цидрак-Цидрак-Цидрони и др.). А в китайских анекдотах смех вызывает трехкомпонентное (фамилия, имя, отчество) и многосложное русское имя (Иван Иваныч Иванов представляется и просится в китайский дом переночевать, но из-за двери ему отвечают: «Вас слишком много» - и не открывают).

Для получения обратной связи и оценки результатов опытно-экспериментальной работы был использован метод анкетирования. Учащимся, владеющим русским языком на уровне Б1 (стажерам), предлагались следующие вопросы:

1. С какими из изученных на уроке фразеологизмов / слов вы уже были знакомы прежде?

2. Какие из них вызвали у вас наиболее сильные эмоции? Какие? Удивление? Возмущение? Гордость? Радость? Какие из них могли бы вызвать коммуникативный шок, если бы вы встретили их в речи русского собеседника без предварительной подготовки?

3. Полезны ли были для вас, как для людей, изучающих русский язык, те сведения, которые вы получили на занятии?

4. Будете ли вы использовать изученные единицы? Если да, то какие?

5. Какие стереотипные представления о России и русских людях существуют в Китае? Отвечая, используйте модели: Русский человек (какой?)...; Россия - страна, в которой ...

6. В каких устойчивых единицах языка эти представления выражаются? Напишите их по-китайски и дайте буквальный перевод на русский, а также значение.

7. Как вы считаете, было бы полезно русским людям, изучающим китайский язык, знать эти единицы, а также стереотипные представления о России и о русских людях, которые существуют в Китае? Зачем? 
Студентам, владеющим языком на уровне А2, предлагались две анкеты: одна в виде таблицы, вторая в виде списка вопросов.

Анкета № 1:

\begin{tabular}{|l|l|l|l|}
\hline $\begin{array}{l}\text { фразеологизм/ } \\
\text { слово }\end{array}$ & $\begin{array}{l}\text { Я слышал(а) это } \\
\text { выражение раньше } \\
\text { да/нет }\end{array}$ & $\begin{array}{l}\text { Теперь буду } \\
\text { употеблять его в } \\
\text { своей речи да/нет }\end{array}$ & $\begin{array}{l}\text { Мои эмоции от этого выражения } \\
\text { (слова): смех удивление, } \\
\text { возмущение и т.д. }\end{array}$ \\
\hline китайская грамота & & & \\
\hline китайские церемонии & & & \\
\hline и т.д. & & & \\
\hline
\end{tabular}

\section{Анкета № 2:}

1. Вы изучили на занятии русские слова и фразеологизмы, в которых отражаются представления русских людей о Китае и китайцах. Эта информация полезна для вас?

2. Что думают в Китае о России и русских людях? Русский человек (какой?) Россия - страна, в которой...

3. В Китае есть фразеологизмы или слова о России и русских людях? Напишите их по-китайски и переведите на русский язык.

4. Сейчас многие русские люди изучают китайский язык. Как Вы думаете, для них полезно знать китайские слова и фразеологизмы о России? Почему?

РЕЗУЛЬТАТЫ И ДИСКУССИЯ. Результатом исследования стало подтверждение эффективности разработанной методики, которая помогает китайским студентам в изучении русских лексических и фразеологических единиц с символьной составляющей о Китае и китайцах. Студенты проявили заинтересованность в теме занятия, делали мало ошибок, выполняя упражнения, что свидетельствует о правильности выбранных методов обучения.

Обработка анкет позволяет убедиться в том, что изучение отобранных единиц актуально для данных групп обучаемых. Студенты отмечали, что полученная на занятиях информация была полезна для них. С большинством данных единиц они познакомились впервые, многие фразеологизмы вызвали у них удивление, которое мы связываем с тем, что для них было неожиданным узнать, какими предстают Китай и китайцы в восприятии русских людей. Большинство отмечаемых студентами эмоций - положительные. Отрицательные эмоции у некоторых обучающихся вызывали фразеологизмы, в которых образы Китая и китайцев являлись негативными. Других студентов те же единицы рассмешили: они поняли иронию, присущую изучаемым фразеологизмам в русском языке.

На вопрос о том, какие китайские фразеологизмы отражают этностереотипы о русских людях, все студенты назвали одну устойчивую единицу战斗民族 (zhandou minzu), которая в переводе означает «боевой народ» или «народ-воин». Следует отметить, что «боевой» в этом фразеологизме не означает «воинственный». В семантике данной единицы русские люди предстают мужественными, несгибаемыми, сильными, независимыми. По мнению китайских студентов, русским людям, изучающим китайский язык, следует ее знать. ЗАКЛЮЧЕНИЕ. Таким образом, проведенное исследование, включающее выявление корпуса лексем и фразеологизмов с символьным компонентом, отражающих представления о Китае и китайцах в русской языковой картине мира, и их анализ; определение методики работы с данными единицами на занятиях по русскому языку как иностранному в китайской аудитории; апробацию и оценку результатов, показало следующее: 1) данная тема является актуальной для методики преподавания РКИ в китайской аудитории; 2) изучение указанных единиц способствует развитию коммуникативных навыков китайских студентов-русистов и позволяет избегать культурного и коммуникативного шока в процессе речевого общения с носителями русского языка; 3) оправданной представляется методика работы с данными единицами (использование таблиц, словарей, интернет-источников, выполнение упражнений, предполагающих обращение к контексту, визуализация образов, сопоставление русских и китайских гетеростереотипов, отражающих представления о национальных особенностях культуры и поведения людей).

\section{LIST OF REFERENCES}

Abramova, V.I., Arkhangelskaya, J.V. (2019) Ot kitayskoy gramoty do dyadyushki Lyao: razvitiye predstavleniy o Kitaye i kitaytsakh $\mathrm{v}$ russkoy yazykovoy kartine mira (na materiale leksiki i frazeologii) [From kitayskaya gramota to dyadyushka Lao: evolution of notions of China and the Chinese in the Russian linguistic picture of the world (on the basis of lexical and phraseological material)]. Bolgarskaya rusistika, (1), 57-69.

Birich, A.K., Mokienko, V.M., Stepanova, L.I. (1999) Slovar russkoy frazeologii. Istoriko-etimologicheskiy spravochnik [Dictionary of Russian phraseology. Historical and etymological reference book]. St. Petersburg: Folio-Press.

Jiehui Ma, Nikolayeva, N.V. (2017) Kitayskiye stereotipy o russkikh v zerkale kitayskikh anekdotov [Chinese stereotypes about the Russians in the mirror of Chinese jokes]. Kultura i tsivilizatsiya, (V. 7 (№ 2A)), 460-466.

Khimik, V.V. (2004) Bolshoy slovar russkoy razgovornoy ekspressivnoy rechi [Large dictionary of Russian colloquial expressive speech]. St. Petersburg: Norint.

Kovshova, M.L. (2012) Lingvokul'turologicheskiy metod vo frazeologii. Kody kul'tury [Linguoculturological method in phraseology. Codes of culture]. Moscow: LENAND. 
Novikova, A.K. (2014) Ob uchote printsipov etnooriyentirovannogo obucheniya v sisteme zanyatiy po RKI (na primere kitayskoy auditorii) [On taking into account the principles of ethno-oriented training in the system of teaching Russian as a foreign language (using the example of Chinese students)]. Russkiy yazyk v sovremennom Kitaye. Chita: ZabGu. (p. 204-206).

Prokhorov, Y.E. (2006) Natsionalnyye, sotsialnyye stereotipy rechevogo obshcheniya i ikh rol v obuchenii russkomu yazyku inostrantsev [National, social stereotypes of speech communication and their role in teaching Russian to foreigners]. Moscow: KoiKniga.

Shanturova, G.A. (2015) K voprosu o roli etnopsikhologicheskikh faktorov v obuchenii RKI kitayskikh studentov-rusistov [On the issue of the role of ethno-psychological factors in teaching Russian as a foreign language to Chinese students studying Russian philology]. Metodika prepodavaniya RKI: traditsii i sovremennost. Moscow: A.S. Pushkin State Institute of Russian Language. (p. 229-236).

Shmelyov, A.D. (2009) Russkaya yazykovaya kartina mira: sistemnyye sdvigi [Russian linguistic picture of the world: systemic changes]. Mir russkogo slova, (4), 14-21.

Slovar sovremennogo russkogo literaturnogo yazyka (1950 - 1965) [Dictionary of the modern Russian literary language]. Moscow Leningrad: Publishing House of the USSR Academy of Sciences.

Ushakov, D.N. (1928 - 1940) Tolkovyy slovar russkogo yazyka [Explanatory dictionary of the Russian language]. Moscow.

Yelistratov V.S. (2010) Tolkovyy slovar russkogo slenga [Explanatory dictionary of Russian slang]. Moscow: AST-PRESS BOOK.

\section{For citation:}

Abramova, V. \& Arkhangelskaya, Ju. (2019) SYMBOLICS OF CHINA REALIA IN RUSSIAN VERBAL CULTURE (IN THE ASPECT OF TEACHING RUSSIAN AS A FOREIGN LANGUAGE). International Scientific-Pedagogical Organization of Philologists “WEST-EAST” (ISPOP). Scientific Journal WEST-EAST. Vol 1/1 N1 (October, 2019). pp. 130-135. doi:

\section{Для цитирования:}

Абрамова, В.И., Архангельская, Ю.В. (2019) СИМВОЛИКА КИТАЙСКОГО В РУССКОЙ ВЕРБАЛЬНОЙ КУЛЬТУРЕ (В АСПЕКТЕ ПРЕПОДАВАНИЯ РКИ) // International Scientific-Pedagogical Organization of Philologists “ WEST-EAST ” (ISPOP). Scientific Journal WEST-EAST. Vol 1/1 N1 (October, 2019). C. 130-135. doi:

Information about the authors: Abramova Veronika - Candidate of Philological Sciences, Associate Professor, Tula State Lev Tolstoy Pedagogical University, Tula, Russia

e-mail: istinijobraz@mail.ru

Arkhangelskaya Julia - Senior Researcher, Tula State Lev Tolstoy Pedagogical University, Tula, Russia

e-mail: archangelju@yandex.ru

Сведения об авторах: Абрамова Вероника Игоревна - кандидат филологических наук, доцент кафедры русского языка и литературы, Тульский государственный педагогический университет им. Л.Н. Толстого, Тула, Россия

e-mail: istinijobraz@mail.ru

Архангельская Юлия Владимировна - старший научный сотрудник кафедры документоведения и стилистики русского языка, Тульский государственный педагогический университет им. Л.Н. Толстого, Тула, Россия

e-mail: archangelju@yandex.ru 